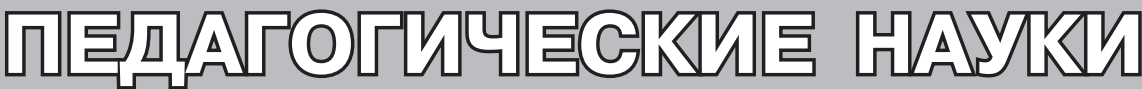

\section{Практико-ориентированное обучение в образовательных организациях высшего образования ФСИН России}

\author{
Э. В. ЗАУТОРОВА \\ Вологодский институт права и экономики ФСИН России, г. Вологда, Рос- \\ сийская Федерация \\ Международная академия наук педагогического образования, г. Москва, \\ Российская Федерация \\ ORCID: https://orcid.org/0000-0002-1334-2654, e-mail: elvira-song@mail.ru
}

\section{Е. В. БОДРОВА}

Университет ФСИН России, г. Санкт-Петербург, Российская Федерация ORCID: https://orcid.org/0000-0003-0629-7522, e-mail: oag.bodrova@mail.ru

\section{Р е фер ат}

Введение: статья посвящена вопросам подготовки обучающихся образовательных организаций высшего образования ФСИН России при использовании имитационных обучающих средств с целью формирования и развития конкретных профессиональных умений и качеств, усиления практической направленности обучения, приобретения и отработки практических навыков. Цель: на основе обобщения опыта применения имитационных средств в процессе подготовки обучающихся образовательных организаций высшего образования ФСИН России показать перспективы построения практико-ориентированной модели образовательного процесса. Методы: теоретический анализ литературы, нормативных правовых актов по проблеме исследования; методы синтеза и обобщения; сравнительно-правовой, эмпирические методы, методы описания, интерпретации. Результаты: анализ использования имитационных средств в процессе подготовки обучающихся образовательных организаций высшего образования ФСИН России способствует формированию универсальных, профессиональных и специальных компетенций, необходимых для самостоятельного несения службы в подразделениях учреждений и органов уголовно-исполнительной системы. Выводы: использование учебных полигонов, учебных рабочих мест, учебных рабочих маршрутов, в том числе с применением AR- и VR-технологий, позволит сформировать у обучающихся четкий алгоритм действий при выполнении служебных обязанностей, а профессорскопреподавательскому составу образовательной организации высшего образования ФСИН России создавать ситуации, максимально приближенные к реальности и условиям исправительного учреждения. Практико-ориентированный подход в обучении способствует качественной подготовке и оптимизации профессиональной адаптации молодых сотрудников к службе в пенитенциарной системе.

К л юче в ы е с ло в а: образовательный процесс; обучающиеся образовательных организаций высшего образования ФСИН России; процесс обучения; практико-ориентированный подход; средства обучения; учебный полигон; учебное рабочее место; учебный рабочий маршрут.

13.00.01 - Общая педагогика, история педагогики и образования. 
Для цитиров ания: Зауторова Э. В., Бодрова Е. В. Практико-ориентированное обучение в образовательных организациях высшего образования ФСИН России. Пенитенциарная наука, 2021, т. 15, № 3 (55), c. 575-584. DOI 10.46741/26869764-2021-15-3-575-584.

\title{
Practice-Oriented Training in Higher Education Institutions of the Federal Penitentiary Service of Russia
}

\author{
EL'VIRA V. ZAUTOROVA \\ Vologda Institute of Law and Economics of FSIN Russia, Vologda, Russian \\ Federation \\ International Academy of Sciences of Pedagogical Education, Moscow, Russian \\ Federation \\ ORCID: https://orcid.org/0000-0002-1334-2654, e-mail: elvira-song@mail.ru
}

\section{ELENA V. BODROVA}

University of FSIN Russia, Saint Petersburg, Russian Federation

ORCID: https://orcid.org/0000-0003-0629-7522, e-mail: oag.bodrova@mail.ru

\begin{abstract}
Introduction: the article considers issues related to the training of students at higher education organizations of the Federal Penitentiary Service of Russia. The type of training under consideration involves the use of simulation training tools to form and develop specific professional skills and qualities, enhance the practical orientation of training, and help students acquire and use practical skills. Aim: to show the prospects for building a practice-oriented model for educational process on the basis of generalization of the experience of using simulation tools in the process of training students at higher education institutions of FSIN Russia. Methods: theoretical analysis of literature and normative legal acts on the problem under consideration; synthesis and generalization; comparative legal method, empirical method, description, interpretation. Results: the analysis of the use of simulation tools in the training of students at higher education organizations of FSIN Russia contributes to the formation of universal, professional and special competencies required for the service in the departments of institutions and bodies of the penal system. Conclusions: the use of training grounds, training workplaces, training work routes, with the use of AR and VR technologies as well, will allow students to form a clear algorithm of actions when performing official duties, and teaching staff of higher education organizations of FSIN Russia - to create situations as close as possible to reality and to the conditions of correctional institutions. A practice-oriented approach to training contributes to high-quality training and optimizes professional adaptation of young officers to the service in the penal system.

Ke y w ords: educational process; students of higher education institutions of FSIN Russia; learning process; practice-oriented approach; learning tools; training ground; training workplace; training work route.
\end{abstract}

13.00.01 - General pedagogy, history of pedagogy and education.

For citation: Zautorova E.V., Bodrova E.V. Practice-oriented training in higher education institutions of the Federal Penitentiary Service of Russia. Penitentiary Science, 2021, vol. 15, no. 3 (55), pp. 575-584. DOI 10.46741/2686-9764-2021-15-3-575-584.

\section{Введение}

Служба в уголовно-исполнительной системе сопряжена с высокими требованиями к профессиональным и психологическим качествам сотрудников, повышенной от- ветственностью за собственные действия, эмоциональным напряжением, моральнопсихологической и физической нагрузками, требующими высокой профессиональной подготовки. Специфика несения службы и 
неготовность молодых сотрудников работать в таких условиях нередко приводят к их увольнению из пенитенциарной системы по собственному желанию. Часто это происходит на первом году службы. Одна из причин увольнения - нарушение адаптации будущих сотрудников к служебной деятельности (профессиональной адаптации) [7; 12]. Так, С. В. Якушкин и М. С. Тарасиков отмечают, что «не все молодые специалисты (выпускники вузов ФСИН России) успешно адаптируются к особенным условиям пенитенциарных учреждений» [10].

Согласно статистическим данным НИИТ ФСИН России численность сотрудников уголовно-исполнительной системы, уволенных на первом году службы без учета стажеров, не прошедших испытательный срок, в 2018 г. составила 868 чел. (3,9 \% от общего числа уволенных), а в 2019 г. этот показатель вырос до 952 чел. (5,53 \% от общего числа уволенных) [8; 10]. К проблемам реализации кадровой политики можно отнести недостаточно высокий уровень профессиональной подготовки сотрудников и текучесть кадров [13], которые, по нашему мнению, взаимосвязаны.

Практико-ориентированный подход в обучении

Федеральные государственные образовательные стандарты высшего профессионального образования (ФГОС ВПО), по которым сейчас осуществляется подготовка специалистов для уголовно-исполнительной системы, ориентированы на достижение «деятельностного результата» образовательного процесса и определяют перечень общих и профессиональных компетенций, приобретение которых позволит успешно осуществлять профессиональную деятельность. В связи с этим возникает необходимость переноса акцентов преподавания из общепрофессиональной теоретической сферы в плоскость практического выполнения конкретных профессиональных задач. Речь идет о практико-ориентированной модели построения образовательного процесса $[14 ; 17 ; 18 ; 20]$.

Вопросами усиления практической направленности профессионального образования занимались В. И. Байденко, В. А. Болотов, В. П. Борисенков, А. А. Вербицкий, А. М. Новиков, В. В. Сериков, В. А. Шершнева и др. Ученые отмечают, что в настоящее время образование в большей мере теоретизированно, что способствует неверному усвоению знаний, полученных обучающимися. При этом действительность требует совершенствовать практические результаты будущей профессиональной деятельности. В этой связи выделяется один из основополагающих принципов образовательного процесса - принцип взаимосвязи теории с практикой, в основе которого лежат закономерности: практика - критерий истины [19; 21], источник познания и область приложения теоретических результатов; практикой проверяется, подтверждается и направляется качество обучения; чем больше приобретаемые обучающимися знания взаимодействуют с жизнью, применяются на практике, используются для преобразования окружающих процессов и явлений, тем выше сознательность обучения и интерес к нему [2; 3; 5].

Несмотря на значимость практико-ориентированного обучения для современного профессионального образования, его содержание и формы еще не получили достаточной теоретической и методической разработки. В ведомственных вузах при подготовке будущих сотрудников уголовноисполнительной системы планированию, организации и проведению практических занятий не уделяется должного внимания, не в полной мере используется потенциал имитационных обучающих средств. В связи с этим обучающиеся слабо ориентируются в профессиональной среде, у них не в достаточной степени сформированы умения и навыки, позволяющие обеспечить в дальнейшем эффективное противодействие противоправному поведению со стороны осужденных и т. д. [16].

Имитационные обучающие средства

Изучением становления практико-ориентированного обучения в ведомственных образовательных организациях занимались Я. С. Ивасенко, Т. И. Краснова, С. П. Мишустин, Е. А. Тимофеева и др. Мы поддерживаем мнение, что совершенствование подготовки будущих сотрудников уголовно-исполнительной системы предполагает создание практико-ориентированных и отвечающих современным требованиям к осуществлению профессиональной деятельности имитационных обучающих средств. Так, использование учебных полигонов, учебных рабочих мест и учебных рабочих маршрутов имеет своей целью не только создание условий для качественного обучения основам профессиональной деятель- 
ности, формирование и развитие конкретных профессиональных умений и качеств сотрудников учреждений и органов уголовно-исполнительной системы, но и усиление практической направленности обучения, приобретение и отработку обучающимися практических навыков, а также закрепление на практике знаний, полученных на занятиях.

Методика проведения занятий с использованием имитационных обучающих средств позволит сформировать у будущих сотрудников интерес к избранной профессии и чувство ответственности, развить организаторские способности, инициативу, волю и настойчивость [1; 16], «погрузить» обучающихся в реалии служебной деятельности. Включение практико-ориентированного подхода в процесс обучения будущих специалистов является необходимым и соответствующим требованиям новых образовательных стандартов и запросам работодателя [11] в образовательных организациях ФСИН России.

Так, учебный полигон представляет собой специально оборудованную учебную территорию, моделирующую условия, максимально приближенные к реальным, и имитирующую реальный объект учреждения уголовно-исполнительной системы, предназначенную для организации и осуществления образовательного процесса, оснащенную собственным оборудованием, инвентарем, техническими средствами обучения. Учебное рабочее место (УРМ) - это специально оборудованное место, оснащенное набором технических средств, приборов, оборудования, нормативных правовых документов, необходимых для выполнения должностных обязанностей сотрудниками учреждений и органов уголовно-исполнительной системы по одной или смежной тематике, предназначенное для проведения как теоретических, так и практических занятий с обучающимися. Такие места могут быть включены в состав учебного полигона, но могут располагаться и в учреждениях и органах уголовно-исполнительной системы. Учебный рабочий маршрут - это маршрутная система обучения, позволяющая достоверно, полно и в комплексе на междисциплинарном уровне обеспечить практическую направленность образовательного процесса, создать условия для максимального приближения к реальным условиям оперативно-служебной деятельности сотрудника ФСИН России.
Материально-техническое и информационно-техническое обеспечение учебного полигона или учебного рабочего места включают в себя: используемые средства обучения (оборудование, техника, расходные материалы, мебель и пр.); программные средства, электронные ресурсы; материалы наглядной агитации в виде стендов, плакатов; руководящие документы и нормативные правовые акты, регламентирующие сферу профессиональной деятельности сотрудника; установленные образцы бланков документов, используемых в деятельности сотрудника; паспорт учебного полигона или учебное рабочее место. При этом если учебное рабочее место позволяет сформировать только узконаправленную часть профессиональной компетенции, то в ходе проведения практических занятий на учебном полигоне можно сформировать компетенцию в целом.

Рассмотрим примеры использования учебного рабочего места, которые можно применять в процессе подготовки будущего сотрудника уголовно-исполнительной системы:

1. Кабинет оперативного работника. Основная цель использования - формирование у обучающихся комплекса теоретических знаний, практических умений и навыков, необходимых для профессионального осуществления оперативно-розыскной деятельности в учреждениях и органах ФСИН России, формирование интереса к избранной профессии и чувства ответственности, развитие организаторских способностей, инициативы, воли и настойчивости, овладение передовыми методами работы, поиск наиболее эффективных способов выполнения профессиональных обязанностей, подготовка будущего специалиста к самостоятельной служебной деятельности.

2. Рабочее место группы управления исправительного учреждения при чрезвычайных обстоятельствах. Основной целью использования является формирование у обучающихся комплекса теоретических знаний, практических умений и навыков, необходимых для профессионального осуществления профилактики, предупреждения и пресечения противоправных действий подозреваемых, обвиняемых и осужденных в виде побега, убийства, массовых беспорядков, групповых неповиновений и др., овладение передовыми методами работы, поиска наиболее эффективных способов 
выполнения профессиональных обязанностей в экстремальных ситуациях.

3. Автоматизированные информационнопоисковые системы, базы данных. Основной целью использования является формирование у обучающихся комплекса теоретических знаний, практических умений и навыков, необходимых для оперативного поиска информации с использованием специализированных программных средств, баз данных, таких как автоматизированная информационная система «Статистика - УИС", программно-технический комплекс автоматизированного картотечного учета спецконтингента в исправительных колониях (ПТК АКУС ИК), система электронного мониторинга подконтрольных лиц (СЭМПЛ), «Розыск-контингент», «Преступления, совершенные подозреваемыми, обвиняемыми, осужденными, содержащимися в учреждениях УИС Российской Федерации» и др., и эффективного документационного сопровождения деятельности сотрудника пенитенциарной системы.

4. Рабочее место сотрудника исправительного учреждения, осуществляющего неотложные следственные действия. Основная цель использования - формирование у обучающихся комплекса теоретических знаний, практических умений и навыков, необходимых для эффективного проведения уголовно-процессуальных мероприятий, входящих в компетенцию органов дознания, по расследованию противоправных действий подозреваемых, обвиняемых и осужденных, совершаемых в исправительных учреждениях и следственных изоляторах уголовно-исполнительной системы.

Таким образом, учебные рабочие места, учебные рабочие маршруты и полигоны представляют собой место проведения учебного занятия, способствующего воссозданию обстановки, приближенной к реальным условиям будущей оперативнослужебной деятельности сотрудников уголовно-исполнительной системы [1].

Использование вышеперечисленных мест проведения учебного занятия с применением средств визуализации информации, в том числе инструментов виртуальной и дополненной реальности, может дать педагогическую эффективность, которая не может быть достигнута при проведении классических учебных занятий. Виртуальная и дополненная реальности (VR и AR) - это современные и быстро развивающиеся технологии. Их цель - расширение физического пространства жизни человека объектами, созданными с помощью цифровых устройств и программ и имеющими характер изображения.

При использовании в образовательном процессе AR- и VR-технологий возможно погружение обучающихся в реалии служебной деятельности: надев очки виртуальной реальности, обучающийся может прикоснуться к модели пистолета Макарова, провернуть его вокруг своей оси, разобрать и собрать, при этом прочитать его тактикотехнические характеристики; надев шлем или очки дополненной реальности, обучающийся имеет возможность погрузиться в определенные заданные преподавателем события в исправительных учреждениях (групповые неповиновения, обысковые мероприятия).

Преимущество виртуальной и дополненной реальностей в том, что они «позволяют создать среду, которая воспринимается человеком через органы ощущения. Фактически VR и AR позволяют смоделировать комфортные условия для получения новых знаний, умений и навыков» [15].

Рассмотрим также варианты использования учебных рабочих маршрутов, в том числе с использованием AR- и VR-технологий, при проведении занятий в образовательных организациях ФСИН России:

1. Прием и распределение подозреваемых, обвиняемых и осужденных по отрядам (камерам). Используется для отработки комплекса умений и навыков по изучению личности осужденного, проведению бесед, сбору, анализу и использованию информации, взаимодействию с другими службами исправительного учреждения. Маршрут: подразделение специального учета $\rightarrow$ помещения штрафного изолятора (ШИЗО), помещение камерного типа (ПКТ) (распределительного блока следственного изолятора (СИЗО), помещение, функционирующее в режиме следственного изолятора (ПФРСИ)) $\rightarrow$ отряд (камера).

2. Оскорбление, нападение на администрацию, угрозы безопасности. Применяется для отработки комплекса умений и навыков по изучению личности осужденного, обстоятельств противоправных действий, проведению опроса фигурантов событий, сбору, анализу и использованию информации, взаимодействию с другими службами 
исправительного учреждения, документированию противоправных действий. Маршрут: оперативный отдел $\rightarrow$ отряд (камера) $\rightarrow$ подразделение специального учета $\rightarrow$ помещения ШИЗО, ПКТ (распределительного блока СИЗО, ПФРСИ).

3. Массовые беспорядки. Отработка комплекса умений и навыков по изучению личности осужденного, обстоятельств противоправных действий, проведению опроса фигурантов событий, сбору, анализу и использованию информации, взаимодействию с другими службами исправительного учреждения, документированию противоправных действий. Маршрут (для отработки в группе): оперативный отдел $\rightarrow$ отряд (камера) $\rightarrow$ подразделение специального учета $\rightarrow$ помещения ШИЗО, ПКТ (распределительного блока СИЗО, ПФРСИ).

4. Неповиновения законным требованиям администрации исправительного учреждения. Используется для отработки комплекса умений и навыков по изучению личности осужденного, обстоятельств противоправных действий, проведению опроса фигурантов событий, сбору, анализу и использованию информации, взаимодействию с другими службами исправительного учреждения, документированию противоправных действий. Маршрут (для отработки в группе): оперативный отдел $\rightarrow$ отряд (камера) $\rightarrow$ подразделение специального учета $\rightarrow$ помещения ШИЗО, ПКТ (распределительного блока СИЗО, ПФРСИ).

5. Розыск. Может применяться для отработки комплекса умений и навыков по сбору, анализу и использованию информации, изучению личности осужденного, обстоятельств противоправных действий, взаимодействию с другими службами исправительного учреждения, документированию противоправных действий. Маршрут (для отработки в группе): оперативный отдел $\rightarrow$ промышленная зона $\rightarrow$ подразделение специального учета $\rightarrow$ отряд (камера).

6. Противодействие поступлению и отправке запрещенных предметов, отправлений, средств. Применяется для отработки комплекса умений и навыков по сбору, анализу и использованию информации, взаимодействию с другими службами исправительного учреждения, профилактике и пресечению противоправных действий, документированию. Маршрут: комната выдачи посылок, передач, бандеролей $\rightarrow$ дежурная часть $\rightarrow$ помещения ШИЗО, ПКТ (распреде- лительного блока СИЗО, ПФРСИ) $\rightarrow$ оперативный отдел.

7. Режим. Используется для отработки комплексных знаний о порядке исполнения и отбывания лишения свободы и меры пресечения в виде заключения под стражу, привития практических навыков и умений по применению норм уголовно-исполнительного права в сфере организации режима в учреждениях уголовно-исполнительной системы Российской Федерации в своей будущей профессиональной деятельности. Маршрут: дежурная часть $\rightarrow$ карантинное отделение $\rightarrow$ помещение распределительного блока СИЗО $\rightarrow$ комната длительных свиданий (комната краткосрочных свиданий) $\rightarrow$ пункт приема посылок, передач, бандеролей.

8. Надзор. Применяется для формирования целостного представления и системы комплексных знаний о порядке исполнения и отбывания наказания в виде лишения свободы, содержания под стражей, выработки умений и навыков в организации надзора в следственных изоляторах. Маршрут: дежурная часть $\rightarrow$ пост оператора видеонаблюдения $\rightarrow$ сборно-следственное отделение (карантинное отделение) $\rightarrow$ камеры $\rightarrow$ комната длительных свиданий (комната краткосрочных свиданий) $\rightarrow$ пункт приема посылок, передач, бандеролей.

9. Охрана. Может быть использована для формирования комплекса умений и навыков по охране исправительных учреждений, производственных объектов уголовно-исполнительной системы; выработке навыков пресечения (ликвидации) групповых неповиновений, массовых беспорядков в СИЗО, навыков розыска и задержания вооруженных и иных особо опасных преступников, совершивших побег из учреждения или при конвоировании, освобождения лиц, захваченных и удерживаемых в качестве заложников в учреждении, а также на других объектах ФСИН России, пресечения (отражения) вооруженных нападений на них, участия в ликвидации последствий чрезвычайных ситуаций природного и техногенного (экологического) характера на объектах уголовно-исполнительной системы Российской Федерации. Маршрут: контрольно-пропускной пункт по пропуску людей на режимную территорию $\rightarrow$ КПП по досмотру автотранспорта $\rightarrow$ караул $\rightarrow$ пульт управления техническими средствами надзора (ПУТСО) $\rightarrow$ место заряжания (разряжения) оружия $[4 ; 6]$. 
10. Конвоирование. Применяется для отработки умений и навыков по конвоированию осужденных, подозреваемых и обвиняемых из учреждений на обменные пункты и обратно, а также между учреждениями уголовно-исполнительной системы территориального органа, если в пунктах дислокации учреждений отсутствуют специальные подразделения по конвоированию. Призван формировать у обучающихся знания требований действующего законодательства и нормативно-правовых актов, регламентирующих деятельность специальных подразделений уголовно-исполнительной системы по конвоированию. Маршрут: КПП по досмотру автотранспорта $\rightarrow$ караул $\rightarrow$ ПУТСО.

К примеру, такие учебные рабочие маршруты, как «Прием и распределение подозреваемых, обвиняемых и осужденных по отрядам (камерам)», «Оскорбление, нападение на администрацию, угрозы безопасности», «Массовые беспорядки», «Неповиновения законным требованиям администрации исправительного учреждения», позволяют сформировать у обучающихся как универсальные, так и общепрофессиональные компетенции согласно федеральному государственному образовательному стандарту высшего образования по специальности 40.05.02 Правоохранительная деятельность, утвержденному приказом Министерства науки и высшего образования Российской Федерации от 28.08.2020 № 1131 [13].

Результаты

Применение на занятиях таких имитационных средств, как учебные полигоны, учебные рабочие места, учебные рабочие маршруты, в том числе с использованием AR- и VR-технологий, направлено на формирование опыта обучающихся при погружении их в профессиональную среду в ходе обучения с целью достижения профессионально и социально значимых компетентностей. Также это обеспечивает вовлечение их в работу, активную деятельность, так как мотивация к изучению теоретического материала идет от потребности в решении практической задачи. В этом случае традиционная дидактическая триада «знания - умения - навыки» дополняется новой дидактической единицей - «опыт деятельности». Такой подход в обучении позволит будущим сотрудникам уверенно и самостоятельно принимать практические решения в области своей профессиональной деятельности.

\section{Заключение}

Таким образом, в настоящее время практическая деятельность играет важную роль в системе профессионального образования. В связи с этим необходимы поиск способов модернизации образовательного процесса, разнообразных методов, приемов и форм организации учебного процесса, а также применение принципиально новых средств обучения для повышения качества профессиональной подготовки сотрудников уголовно-исполнительной системы.

Применение учебных полигонов, учебных рабочих мест, учебных рабочих маршрутов позволит сформировать у обучающихся четкий алгоритм действий при выполнении служебных обязанностей, а профессорскопреподавательскому составу образовательной организации высшего образования ФСИН России даст возможность моделировать ситуации, максимально приближенные к реальной действительности и условиям исправительного учреждения [5; 9]. Практико-ориентированное использование AR- и VR-технологий в сочетании с учебными полигонами, учебными рабочими местами, учебными рабочими маршрутами улучшит успеваемость обучающихся, понимание теоретического материала, повысит уровень мотивации. Все то, что не может быть создано в реальном образовательном процессе по техническим, экономическим или физическим причинам, может быть создано в мире виртуальном.

Практико-ориентированный подход в обучении не только способствует качественной подготовке, формированию необходимых в служебной деятельности универсальных, профессиональных и специальных компетенций для самостоятельного несения службы в подразделениях учреждений и органов уголовно-исполнительной системы, но и в последующем оптимизирует профессиональную адаптацию молодых сотрудников к службе в пенитенциарной системе. 


\section{СПИСОК ЛИТЕРАТУРЫ}

1. Батищева, Е. В. Учебные рабочие места и их роль в подготовке специалистов для УИС / Е. В. Батищева // Ведомости уголовно-исполнительной системы. - 2014. - № 6 (145). - С. 46-48.

2. Брызгалова, И. В. Активизация учебно-познавательной деятельности курсантов образовательных организаций высшего образования ФСИН России как педагогическая проблема / И. В. Брызгалова // Международный пенитенциарный журнал. - 2016. - № 2 (6). - С. 62-66.

3. Брызгалова, И. В. Учебные игры как интерактивная форма проведения занятий в вузах ФСИН России / И. В. Брызгалова, Э. В. Зауторова // Профессиональное образование и наука. - 2018. - № 4 (5). - С. 12-18.

4. Викторова, Т. В. Модель процесса формирования морально-психологической устойчивости к применению оружия сотрудниками отдела охраны ФСИН России / Т. В. Викторова // Современное педагогическое образование. 2020. - № 10. - С. 227-230.

5. Дазмарова, Т. Н. Реализация практико-ориентированного подхода в обучении курсантов академии ФСИН России с использованием учебного рабочего места / Т. Н. Дазмарова // Субъекты образовательной деятельности в образовательном пространстве вузов: взаимодействие, саморазвитие, сотрудничество : сборник материалов по итогам IV Межвузовских учебно-методических сборов профессорско-преподавательского и начальствующего состава образовательных организаций ФСИН России. - Рязань : Академия ФСИН России, 2016. - С. 24-29. - ISBN 978-5-7743-0780-7.

6. Зауторова, Э. В. Морально-психологическая устойчивость - ведущая составляющая эффективности профессиональной деятельности сотрудников отдела охраны исправительных учреждений ФСИН России / Э. В. Зауторова, Т. В. Викторова // Ведомости уголовно-исполнительной системы. - 2018. - № 9 (196). - С. 11-18.

7. Зауторова, Э. В. Профессионально-педагогическая компетентность сотрудников уголовно-исполнительной системы и исправление осужденных / Э. В. Зауторова // Уголовно-исполнительная система: право, экономика, управление. - 2020. - № 3. - С. 34-37.

8. Кадровое обеспечение уголовно-исполнительной системы : информационно-аналитический сборник / под общей редакцией первого заместителя директора ФСИН России А. А. Рудого. - Тверь : НИИТ ФСИН России, 2019. $85 \mathrm{c.}$

9. Кевля Ф. И. Специфика профессиональной деятельности и личностные особенности сотрудников ФСИН России / Ф. И. Кевля, Э. В. Зауторова // Актуальные проблемы организации деятельности органов и учреждений уголовноисполнительной системы и пути их решения : материалы межвузовской научно-практической конференции, посвященной памяти заслуженного деятеля науки РСФСР, доктора юридических наук, профессора А. И. Зубкова и Дню российской науки. - Рязань : АПУ ФСИН России, 2020. - С. 117-121.

10. Кусакин, А. Н. Профессиональная адаптация выпускников Академии ФСИН России к функциональной деятельности сотрудника уголовно-исполнительной системы : аналитический обзор / А. Н. Кусакин, С. В. Якушкин, М. С. Тарасиков. - Рязань : Академия ФСИН России, 2007. - 30 с.

11. Мишустин, С. П. Организация практико-ориентированного подхода в обучении курсантов ФСИН России / С. П. Мишустин. - URL: http://lexandbusiness.ru/view-article.php?id=2421(дата обращения: 24.09.2020).

12. Об образовании в Российской Федерации : федеральный закон от 29.12.2012 № 273-Ф3. - URL. http://ivo. garant.ru/\#/document/70291362/paragraph/1/highlight/Ф3-273:1 (дата обращения: 19.09.2020).

13. Об утверждении федерального государственного образовательного стандарта высшего образования - специалитет по специальности 40.05.02 Правоохранительная деятельность : приказ Министерства науки и высшего образования Российской Федерации от 28.08.2020 № 1131. - URL: http://publication.pravo.gov.ru/Document/ View/0001202009150044 (дата обращения: 24.09.2020).

14. Степанова, О.Н.Особенности профессиональной адаптации молодых сотрудников к службе в УИС / О. Н. Степанова // Психология и педагогика: методика и проблемы практического применения. - 2010. - № 11-1. - С. 226231.

15. Технологии AR и VR в образовании. - URL: https://habr.com/ru/company/mailru/blog/435996/ (дата обращения: 01.08.2021).

16. Хотькина, О. К. Использование учебного рабочего места «Инспектор отдела специального учета» в реализации практической направленности обучающихся / О. К. Хотькина // Организация образовательного процесса в вузах: современное состояние, проблемы и перспективы : сборник материалов научно-методической конференции. Рязань : Академия ФСИН России, 2017. - С. 275-280. - ISBN 978-5-7743-0817-0.

17. Bazhenova, N. G. Psychological characteristics of students' self-organization: Personal and group levels / N. G. Bazhenova, R. I. Bazhenov // Modern Journal of Language Teaching Methods (MJLTM). - 2018. - Volume 8, issue 6. - Pp. 11-18.

18. Balikaeva, M. B. The interconnection between future engineers' professional mobility in higher school social and cultural environment / M. B. Balikaeva // Modern Journal of Language Teaching Methods (MJLTM). -2018. - Volume 8, Issue 6. - Pp. 70-78.

19. Cárdenas-Robledo, L. A. Ubiquitous learning to enhance lab practice / L. A. Cárdenas-Robledo, A. Peña-Ayala // Modern Journal of Language Teaching Methods (MJLTM). - 2018. - Volume 8, issue 6. - Pp. 62-69.

20. The Model Of Supporting Technical Students In Their Professional Self-Definition / E. V. Zautorova, L. V. Konovalova A. V. Vilkova, V. M. Litvishkov, F. I. Kevlya // Modern Journal of Language Teaching Methods (MJLTM). - 2018. - Volume 8, issue 6. - Pp. 426-431.

21. University Pedagogical System And Its Focus On Destructive Student Behavior Overcoming / A. V. Kiryakova, A. V. Samigulina, E. R. Khairullina, A. Ya. Melnikova, R. R. Denisova, A. M. Ishmuradova // Modern Journal of Language Teaching Methods (MJLTM). - 2018. - Volume 8, issue 6. - Pp. 223-232.

\section{REFERENCES}

1. Batishcheva E.V. Training workplaces and their role in the training of specialists for the penal system. Vedomosti ugolovnoispolnitel'noi sistemy=Bulletin of the Penal System, 2014, no. 6 (145), pp. 46-48. (In Russ.). 
2. Bryzgalova I.V. Boosting the educational and cognitive activity in cadets of higher education organizations of the Federal Penitentiary Service of Russia as a pedagogical problem. Mezhdunarodnyi penitentsiarnyi zhurnal=International Penitentiary Journal, 2016, no. 2 (6), pp. 62-66. (In Russ.).

3. Bryzgalova I.V., Zautorova E.V. Educational games as an interactive form of conducting classes in universities of the Federal Penitentiary Service of Russia. Professional'noe obrazovanie i nauka=Professional Education and Science, 2018, no. 4 (5), pp. 12-18. (In Russ.).

4. Viktorova T.V. Model of the process of forming moral and psychological resistance to the use of firearms by employees of the security Department of the Federal Penitentiary Service of Russia. Sovremennoe pedagogicheskoe obrazovanie=Modern Pedagogical Education, 2020, no. 10, pp. 227-230. (In Russ.).

5. Dazmarova T.N. Implementation of a practice-oriented approach in training cadets of the Academy of the Federal Penitentiary Service of Russia using educational workplaces. In: Sub"ekty obrazovatel'noi deyatel'nosti v obrazovatel'nom prostranstve vuzov: vzaimodeistvie, samorazvitie, sotrudnichestvo: sbornik materialov po itogam IV mezhvuzovskikh uchebno-metodicheskikh sborov professorsko-prepodavatel'skogo i nachal'stvuyushchego sostava obrazovatel'nykh organizatsii FSIN Rossii [Subjects of educational activity in the educational space of universities: interaction, selfdevelopment, cooperation: proceedings of the 4th inter-university educational and methodological session of the teaching staff and the commanding staff of educational organizations of the Federal Penitentiary Service of Russia]. Ryazan: Akademiya FSIN Rossii, 2016. Pp. 24-29. (In Russ.).

6. Zautorova E.V., Viktorova T.V. Moral and psychological stability - the leading component of the effectiveness of professional activity of employees of the security department of correctional institutions of the Federal Penitentiary Service of Russia. Vedomosti ugolovno-ispolnitel'noi sistemy=Bulletin of the Penal System, 2018, no. 9 (196), pp. 11-18. (In Russ.).

7. Zautorova E.V. Professional and pedagogical competence of employees of the penal system and reformation of convicts. Ugolovno-ispolnitel'naya sistema: pravo, ekonomika, upravlenie=Criminal-Executory System: Law, Economy, Management, 2020, no. 3, pp. 34-37. (In Russ.).

8. Zautorova E.V., Kevlya F.I. Specifics of professional activity and personal characteristics of employees of the Federal Penitentiary Service of Russia. In: Aktual'nye problemy organizatsii organov UIS i puti ikh resheniya : materialy mezhvuzovskoi nauchno-prakticheskoi konferentsii, posvyashchennoi pamyati zasluzhennogo deyatelya nauki RSFSR, doktora yuridicheskikh nauk, professora A. I. Zubkova i Dnyu rossiiskoi nauki [Topical issues of organization of the bodies of the penal system and the ways to solve them: proceedings of the inter-university research-to-practice conference dedicated to the memory of the Honored Scientist of the RSFSR, Doctor of Sciences (Law), Professor A.I. Zubkov and the Day of Russian Science]. Ryazan: APU FSIN Rossii, 2020. Pp. 117-121. (In Russ.).

9. Rudoi A.A. (Ed.). Kadrovoe obespechenie ugolovno-ispolnitel'noi sistemy. Informatsionno-analiticheskii sbornik [Staffing of the penal system. Information and analytical collection]. Tver': NIIT FSIN Rossii, 2019. 85 p.

10. Kusakin A.N., Yakushkin S.V., Tarasikov M.S. Professional'naya adaptatsiya vypusknikov Akademii FSIN Rossii $k$ funktsional'noi deyatel'nosti sotrudnika ugolovno-ispolnitel'noi sistemy: analiticheskii obzor [Professional adaptation of graduates of the Academy of FSIN Russia to the work of an employee of the penal system: an analytical review]. Ryazan: Akademiya FSIN Rossii, 2007. 30 p.

11. Mishustin S.P. Organizatsiya praktiko-orientirovannogo podkhoda v obuchenii kursantov FSIN Rossii [Organization of a practice-oriented approach in the training of cadets of the Federal Penitentiary Service of Russia]. Available at: http:// lexandbusiness.ru/view-article.php?id=2421 (accessed September 24, 2020).

12. Ob obrazovanii v Rossiiskoi Federatsii: federal'nyi zakon ot 29.12.2012 № 273-FZ [On education in the Russian Federation: Federal Law 273-FZ of December 29, 2012]. Available at: http://ivo.garant.ru/\#/document/70291362/ paragraph/1/highlight/FZ-273:1 (accessed September 19, 2020).

13. Ob utverzhdenii federal'nogo gosudarstvennogo obrazovatel'nogo standarta vysshego obrazovaniya - spetsialitet po spetsial'nosti 40.05.02 Pravookhranitel'naya deyatel'nost': prikaz Ministerstva nauki i vysshego obrazovaniya Rossiiskoi Federatsii ot 28.08.2020 № 1131 [On approval of the federal state educational standard of higher education - specialist's program, specialty 40.05.02 - law enforcement: Order of the Ministry of Science and Higher Education of the Russian Federation dated August 28, 2020 No. 1131]. Available at: http://publication.pravo.gov.ru/Document/ View/0001202009150044 (accessed September 24, 2020).

14. Stepanova O.N. Features of professional adaptation of young employees to serve in the penal system. Psikhologiya i pedagogika: metodika i problemy prakticheskogo primeneniya = Psychology and Pedagogy: Methods and Problems of Practical Application, 2010, no. 11-1, pp. 226-231. (In Russ.).

15. Tekhnologii AR i VR v obrazovanii [AR and VR technologies in education]. Available at: https://habr.com/ru/company/ mailru/blog/435996/ (accessed August 1, 2021).

16. Khot'kina O.K. The use of the training workplace "Inspector of the special accounting department" in the implementation of the practical orientation of students. In: Organizatsiya obrazovatel'nogo protsessa $v$ vuzakh: sovremennoe sostoyanie, problemy i perspektivy: sbornik materialov nauchno-metodicheskoi konferentsii [Organization of the educational process in universities: current state, problems and prospects: proceedings of a scientific and methodological conference]. Ryazan: Akademiya FSIN Rossii, 2017. Available at: https://elibrary.ru/item.asp?id=29728294 (accessed September 20, 2020). (In Russ.).

17. Bazhenova N.G., Bazhenov R.I. Psychological characteristics of students' self-organization: Personal and group levels. Modern Journal of Language Teaching Methods (MJLTM), 2018, June, vol. 8, no. 6, pp. 11-18.

18. Balikaeva M.B. The interconnection between future engineers' professional mobility in higher school social and cultural environment. Modern Journal of Language Teaching Methods (MJLTM), 2018, June, vol. 8, no. 6, pp. 70-78.

19. Cárdenas-Robledo L.A., Peña-Ayala A. Ubiquitous learning to enhance lab practice. Modern Journal of Language Teaching Methods (MJLTM), 2018, June, vol. 8, no. 6, pp. 62-69.

20. Zautorova E.V., Konovalova L.V., Vilkova A.V., Litvishkov V.M., Kevlya F.I. The model of supporting technical students in their professional self-definition. Modern Journal of Language Teaching Methods (MJLTM), 2018, June, vol. 8, no. 6, pp. 426-431.

21. Kiryakova A.V., Samigulina A.V., Khairullina E.R., Melnikova A.Ya., Denisova R.R., Ishmuradova A.M. University pedagogical system and its focus on destructive student behavior overcoming. Modern Journal of Language Teaching Methods (MJLTM), 2018, June, vol. 8, no. 6, pp. 223-232. 


\section{СВЕДЕНИЯ ОБ АВТОРАХ / INFORMATION ABOUT THE AUTHORS}

ЭЛЬВИРА ВИКТОРОВНА ЗАУТОРОВА - ДОКТОР педагогических наук, профессор, профессор кафедры юридической психологии и педагогики психологического факультета Вологодского института права и экономики ФСИН России, членкорреспондент Международной академии наук педагогического образования, г. Вологда, Российская Федерация, ORCID: https://orcid.org/00000002-1334-2654, e-mail: elvira-song@mail.ru

ЕЛЕНА ВИКТОРОВНА БОДРОВА - СтаршИЙ преподаватель-методист группы методического обеспечения учебного процесса учебного отдела Университета ФСИН России, г. Санкт-Петербург, Российская Федерация, ORCID: https://orcid.org/0000-0003-0629-7522, e-mail: oag.bodrova@mail.ru
EL'VIRA V. ZAUTOROVA - Doctor of Sciences (Pedagogy), Professor, professor at the Department of Legal Psychology and Pedagogy, Psychological Faculty, Vologda Institute of Law and Economics of FSIN Russia, Vologda, Russian Federation, corresponding member of the International Academy of Sciences of Pedagogical Education, Moscow, Russian Federation, ORCID: https://orcid.org/0000-00021334-2654, e-mail: elvira-song@mail.ru

ELENA V. BODROVA - senior lecturer and teacher trainer, group for methodological support of educational process, Department of Education, University of FSIN Russia, Saint Petersburg, Russian Federation, ORCID: https://orcid. org/0000-0003-0629-7522, e-mail: oag.bodrova@mail.ru

Статья поступила 29.09.2020 